\title{
Maternal characteristics and risk factors for preeclampsia in pregnant women
}

\author{
Características maternas e fatores de risco para pré-eclâmpsia em gestantes
}

Eilen Tainá Matos Ferreira ${ }^{1}$, Nádya dos Santos Moura ${ }^{2}$, Maria Luziene de Sousa Gomes ${ }^{2}$, Erielton Gomes da Silva ${ }^{1}$, Maria das Graças da Silva Guerreiro ${ }^{3}$, Mônica Oliveira Batista Oriá ${ }^{2}$

Objective: to investigate maternal characteristics and risk factors for development of preeclampsia in pregnant women. Methods: documentary and retrospective study based on medical records of pregnant women of six Family Health Strategy teams. Information of 94 pregnant women was collected through a form and used in the study. Results: the pregnant women were aged between 15 and 47 years. The risk factors for development of preeclampsia in the sample were primiparity 40 (42.6\%), chronic hypertension $4(4.3 \%)$, multiple pregnancy $9(9.6 \%)$, diabetes mellitus and obesity $8(8.6 \%)$, and age $>40$ years $(1.1 \%)$. Conclusion: there were some risk factors for the development of preeclampsia in the evaluated registries, such as primiparity, chronic hypertension, diabetes mellitus and obesity.

Descriptors: Risk Factors; Pre-Eclampsia; Prenatal Care; Pregnancy, High-Risk.

Objetivo: investigar as características maternas e os fatores de risco para o desenvolvimento da pré-eclâmpsia em gestantes. Métodos: estudo documental e retrospectivo, conduzido em fichas de cadastro de gestantes de seis equipes da Estratégia Saúde da Família. Foram utilizadas as informações de 94 gestantes, sendo esses dados coletados por meio de um formulário. Resultados: as gestantes possuíam idade entre 15 e 47 anos. Os fatores de risco para o desenvolvimento de pré-eclâmpsia presentes na amostra foram a primiparidade $40(42,6 \%)$, a hipertensão crônica $4(4,3 \%)$, a gravidez múltipla $9(9,6 \%)$, o diabetes mellitus e a obesidade $8(8,6 \%)$ e a idade $>40$ anos $(1,1 \%)$. Conclusão: houve a presença de alguns fatores de risco para o desenvolvimento da pré-eclâmpsia nos cadastros avaliados, como primiparidade, hipertensão crônica, diabetes mellitus e obesidade. Descritores: Fatores de Risco; Pré-Eclâmpsia; Cuidado Pré-Natal; Gravidez de Alto Risco.

\footnotetext{
${ }^{1}$ Universidade Federal do Piauí. Picos, PI, Brazil.

${ }^{2}$ Universidade Federal do Ceará. Fortaleza, CE, Brazil.

${ }^{3}$ Centro Universitário Estácio do Ceará. Fortaleza, CE, Brazil. 


\section{Introduction}

Although pregnancy is a natural physiological state, it is a period marked by physical and mental changes that must be treated in a unique way and, as such, receive care and support from qualified professionals. In this context, prenatal care aims to ensure that women receive quality care to promote the development of a pregnancy without complications, and to protect against and prevent adverse events related to obstetric health $^{(1)}$.

Despite advances in the quality of prenatal care, data have shown worrying indicators. In this context, hypertensive syndromes ranks first among the causes of maternal deaths in developing countries, and it is responsible for about $14.0 \%$ of all maternal deaths worldwide ${ }^{(2)}$. Preeclampsia, a major international maternal health problem with high lethality and morbidity, whose onset occurs usually in the second half of pregnancy, is also noteworthy ${ }^{(3)}$.

Preeclampsia is defined as a multisystemic disease characterized by a combination of elevated blood pressure (systolic BP $\geq 140 \mathrm{mmHg}$ or diastolic $\mathrm{BP} \geq 90 \mathrm{mmHg}$ ), first identified after 20 weeks of gestation, and proteinuria, and may coincide with another hypertensive state ${ }^{(4)}$.

That said, it is necessary to screen pregnant women at high risk for development of this condition in order to reduce its prevalence through pharmacological intervention in high-risk groups, and minimize adverse perinatal events in the case of women who experienced preeclampsia. This can be done through appropriate and timely interventions, in an attempt to reduce the number of deaths and complications resulting from such disease ${ }^{(5-7)}$.

In this regard, one measure to prevent the progression of preeclampsia to more serious complications is a good prenatal monitoring. In this sense, the role of nurses stands out in the assistance to this public and in the early identification of obstetric complications, resulting in reduction of maternal and fetal mortality.
Thus, this study investigates maternal characteristics and risk factors for the development of preeclampsia in pregnant women as fundamental for the provision of care aimed at reducing complications for mother and child, such as lower hospitalization and mortality rates.

\section{Methods}

Documentary, retrospective study carried out between August and December 2017. Data were collected from medical records of pregnant women of six Family Health Strategy teams of a municipality in the state of Piauí, which has about 79.159 thousand inhabitants and 36 Family Health Strategy teams, 25 of which are located in the urban area and 11 in the rural area.

As this was a retrospective study, the six teams with the largest number of pregnant women were selected in the "Prenatal, Childbirth and Puerperium Follow-up and Evaluation System" (Stork Network Information System). This system allows the registration, follow-up, and evaluation of prenatal and puerperium care provided by health services to each pregnant woman and newborn. The period surveyed was from January 2016 to January 2017. This strategy resulted in an initial sample of 259 records. The selection of the sample was non-probabilistic and for convenience, respecting the inclusion criteria of the study, and resulted in 94 records.

The inclusion criteria were: the Family Health Strategy units should be in the urban area; the pregnant woman should have done the five examinations on the list of indicators (hemogram, Venereal Disease Research Laboratory, glycemia, uroculture, and Human Immunodeficiency Virus testing) and should present the pregnancy outcome card. Records with a history of miscarriage in the current gestation were excluded.

A form addressing data on the sociodemographic profile and characteristics of the mothers was used. The information included: clinical and family his- 
tory, and risk factors for development of preeclampsia in the current gestation. The risk factors were: primiparity, history of preeclampsia in previous gestations, chronic hypertension or chronic renal disease or both, history of thrombophilia, multifocal pregnancy, in vitro fertilization, family history of preeclampsia, type 1 or type 2diabetes mellitus, obesity, systemic lupus erythematosus, and advanced age of the mother (over 40 years $)^{(7)}$. For the classification of systolic and diastolic blood pressure, we considered the 7th Brazilian Arterial Hypertension Directive ${ }^{(8)}$.

Data were analyzed statistically in the Statistical Package for the Social Sciences, version 20.0. Descriptive statistics, using absolute and relative frequencies, standard deviation and means, were performed. Bivariate analyses using the Chi-Square test $\left(\mathrm{x}^{2}\right)$ were also carried out to measure the association between categorical variables. The level of significance adopted was $\mathrm{p} \leq 0.05$. The data are presented in tables.

This research was approved by the Human Research Ethics Committee of the Federal University of Piauí, according to opinion no 2,344,647, and was conducted in accordance with Brazilian guidelines and standards for research involving human beings (Resolution no 466/2012). The participation of the Family Health Strategy teams occurred after presentation and agreement with the Term of Commitment and Use of Data.

\section{Results}

This study involved 94 pregnant women enrolled in the Prenatal, Childbirth and Puerperium Follow-up and Evaluation System, aged 15 to 47 years, with an age range of $25.44( \pm 5.8)$ years, who concluded the high school 25 (26.6\%), lived with a partner 30 (31.9\%) and were brown skinned 53 (53.4\%). The data about maternal characteristics of the current gestation are described in Table 1.
Table 1 - Distribution of pregnant women according to the maternal characteristics of the current gesta-

\begin{tabular}{|c|c|}
\hline Variables & $n(\%)$ \\
\hline \multicolumn{2}{|c|}{ Previous gestations } \\
\hline None & $40(42.6)$ \\
\hline $1-3$ & $46(48.9)$ \\
\hline$\geq 4$ & $8(8.5)$ \\
\hline \multicolumn{2}{|c|}{ Parity ( ${ }^{\circ}$ of children) } \\
\hline None & $50(53.2)$ \\
\hline $1-3$ & $36(38.5)$ \\
\hline$\geq 4$ & $8(8.3)$ \\
\hline \multicolumn{2}{|c|}{ Vaginal births $(n=27)$} \\
\hline $1-3$ & $22(23.6)$ \\
\hline$\geq 4$ & $5(5.1)$ \\
\hline \multicolumn{2}{|c|}{ Cesarean births $(n=17)$} \\
\hline $1-3$ & $14(14.9)$ \\
\hline$\geq 4$ & $3(3.2)$ \\
\hline \multicolumn{2}{|c|}{ Miscarriages } \\
\hline None & $84(89.3)$ \\
\hline 1 & $6(6.3)$ \\
\hline $2-3$ & $4(4.4)$ \\
\hline \multicolumn{2}{|c|}{ Live births $(n=40)$} \\
\hline $1-3$ & $37(39.4)$ \\
\hline$\geq 4$ & $3(3.2)$ \\
\hline \multicolumn{2}{|c|}{ Stillborns $(n=44)$} \\
\hline None & $40(53.1)$ \\
\hline 1 & $4(4.3)$ \\
\hline \multicolumn{2}{|c|}{ Live children at present $(n=40)$} \\
\hline $1-3$ & 37 (39.4) \\
\hline$\geq 4$ & $3(3.2)$ \\
\hline
\end{tabular}

Regarding the data of the current pregnancy, 40 (42.6\%) were primiparous, 4 (4.3\%) had systemic arterial hypertension, 9 (9.6\%) had multiple pregnancies, 8 (8.6\%) were diabetic and obese, and $1(1.1 \%)$ was over 40 years of age. In summary, the maternal characteristics that had significant association with systolic and diastolic blood pressure were primiparity $(\mathrm{p}=0.006)$, chronic hypertension $(\mathrm{p}=0.001)$, diabetes mellitus $(p=0.009)$, and obesity $(p=0.009)$. Data on prior preeclampsia, history of thrombophilia, family history of preeclampsia, and in vitro fertilization were not found in the sample (Table 2). 
Table 2 - Relationship between maternal characteristics and systolic and diastolic arterial hypertension $(n=4)$

\begin{tabular}{|c|c|c|c|c|c|c|c|c|}
\hline \multirow{3}{*}{ Variables } & \multirow{2}{*}{\multicolumn{3}{|c|}{$\begin{array}{c}\text { Systolic Blood Pressure (mmHg) } \\
\text { n (\%) }\end{array}$}} & \multirow{3}{*}{ p } & \multicolumn{3}{|c|}{ Diastolic Blood Pressure (mmHg) } & \multirow{3}{*}{$\mathbf{p}$} \\
\hline & & & & & & n (\%) & & \\
\hline & $<120$ & 121-139 & $140-159$ & & $\leq \mathbf{8 0}$ & 81-89 & $90-99$ & \\
\hline \multicolumn{9}{|l|}{ Primiparity } \\
\hline Yes & $38(41.3)$ & - & $2(2.2)$ & 0.006 & $38(41.3)$ & $1(1.1)$ & $1(1.1)$ & 0.881 \\
\hline No & $51(53.2)$ & $1(1.1)$ & $2(2.2)$ & & $51(53.3)$ & - & $3(3.2)$ & \\
\hline \multicolumn{9}{|c|}{ Chronic hypertension } \\
\hline Yes & $2(2.1)$ & $1(1.1)$ & $1(1.1)$ & 0.001 & $3(3.2)$ & - & $1(1.1)$ & 0.325 \\
\hline No & $82(87.2)$ & - & $3(3.2)$ & & $81(86.2)$ & $1(1.1)$ & $3(3.2)$ & \\
\hline Not filled & $5(5.3)$ & - & - & & $5(5.3)$ & - & - & \\
\hline \multicolumn{9}{|c|}{ Multiple gestation } \\
\hline Yes & $9(9.6)$ & - & - & 0.439 & $8(8.5)$ & $1(1.1)$ & - & 0.023 \\
\hline No & $20(21.3)$ & $1(1.1)$ & $1(1.1)$ & & 20 (21.3) & - & $2(2.1)$ & \\
\hline Not filled & $60(63.8)$ & - & $3(3.2)$ & & $61(64.9)$ & - & $2(2.1)$ & \\
\hline \multicolumn{9}{|c|}{ Diabetes mellitus } \\
\hline Yes & $6(6.4)$ & $1(1.1)$ & $1(1.1)$ & 0.009 & $7(7.4)$ & - & $1(1.1)$ & 0.326 \\
\hline No & $23(24.5)$ & - & - & & $21(22.3)$ & $1(1.1)$ & $1(1.1)$ & \\
\hline Not filled & $60(63.8)$ & - & $3(3.2)$ & & $61(64.9)$ & - & $2(2.1)$ & \\
\hline \multicolumn{9}{|l|}{ Obesity } \\
\hline Yes & $6(6.4)$ & $1(1.1)$ & $1(1.1)$ & 0.009 & $7(7.4)$ & - & $1(1.1)$ & 0.326 \\
\hline No & $23(24.5)$ & - & - & & 21 (22.3) & $1(1.1)$ & $1(1.1)$ & \\
\hline Not filled & $60(63.8)$ & - & $3(3.2)$ & & $61(64.9)$ & - & $2(2.1)$ & \\
\hline \multicolumn{9}{|c|}{ Maternal age (years) } \\
\hline$<40$ & $88(93.6)$ & $1(1.1)$ & $4(4.3)$ & 0.972 & $88(93.6)$ & $1(1.1)$ & $4(4.3)$ & 0.972 \\
\hline$>40$ & $1(1.1)$ & - & - & & $1(1.1)$ & - & - & \\
\hline
\end{tabular}

\section{Discussion}

The collection of data only from records of pregnant women assisted by six Family Health Strategy teams of the urban zone which had the largest number of pregnant women in a year represented a limitation of this study because it does not allow the collection of information from other areas of the city. Another limitation was that the records were not adequately filled or incomplete, preventing the collection of all the variables predicted in this research. Furthermore, this was a cross-sectional study, and therefore, the longitudinal follow-up of the outcomes of these pregnancies and knowing the impact that maternal characteristics and risk factors had on the women's health were not possible.
Studies on the early identification of maternal characteristics and risk factors for preeclampsia are sorely needed for the application of adequate and specific care, and to reduce morbidity and mortality rates and costs resulting from hospitalizations of mothers and children. Studies indicate that the short-term cost of preeclampsia for the US health system is $\$ 2.18$ billion per year ${ }^{(9)}$, with a consequent improvement in the quality of life.

In general, the screening for preeclampsia is an approach that investigates clinical risk factors and maternal characteristics in order to identify women at high risk of developing preeclampsia. However, it is capable of tracking only $35.0 \%$ of all cases of this di- 
sease and approximately $40.0 \%$ of early preeclampsia, presenting a $10.0 \%$ false positive rate $^{(9)}$.

In view of this discussion, it is essential to take into account other factors: the associations between hypertensive complications and body mass index, age, previous preeclampsia, clinical history and biochemical markers such as protein $\mathrm{A}$ associated with placental growth factor and uterine artery Doppler ${ }^{(7-10)}$. However, Brazil still does not have the necessary financial resources to offer all these predictive tests in the Unified Health System on a large scale. For this reason, it is fundamental to analyze the maternal characteristics and risk factors during prenatal consultations because both are cheap and have good predictive value, so that they can be adopted by the Unified Health System, thus transforming prenatal care.

Anamnesis and physical examination are excellent to detect predictors of preeclampsia, particularly when linked to the patient's personal history (nulliparity, age, family history, history of preeclampsia, hypertension, renal disease, thyroid disease, multiple gestation, etc.).

Evaluating maternal characteristics and risk factors for the development of preeclampsia is a practical, inexpensive and easy-to-perform measure that can be adopted by any professional in the Family Health Strategy. Moreover, this measures is effective to detect pregnant at high risk and is associated with a detection rate of new cases of up to $35.0 \%{ }^{(7-9)}$.

In the context of early screening for preeclampsia, maternal age is a determining factor for complications during pregnancy. Gestation in old age is considered risky in terms of preeclampsia. In the present study, the mean age of the women was 25 years; most of them were outside the age risk group for preeclampsia, similar to the findings of other studies that analyzed this theme $\mathrm{e}^{(10-11)}$.

Another risk factor for preeclampsia is primiparity. The present findings were contrary to other studies in which the chances of developing preeclampsia are higher in primiparous women ${ }^{(12-13)}$.
Regarding the presence of arterial hypertension and family history of diabetes in the evaluated population, scholars point out that they are risk factors associated with the development of hypertensive disorders during pregnancy. In 88 women evaluated, the estimated prevalence of gestations complicated by hypertensive disorders was of $9.5 \%{ }^{(14)}$.

Chronic hypertension and diabetes were morbid associations present in the history of $24.0 \%$ and $60.0 \%$, respectively, of pregnant women with hypertensive syndromes who sought assistance from the Family Health Strategy. Furthermore, preeclampsia occurs more frequently in women who are genetically predisposed and who have a confirmed family history of hypertension $^{(15)}$.

Considered also as a risk factor, obesity can lead to unfavorable outcomes for both mother and child. Such outcomes include dystocia, hypertension and diabetes ${ }^{(16)}$, so a $10.0 \%$ difference in pre-gestational body mass index is associated to change of at least $10.0 \%$ in the risk of preeclampsia and gestational diabetes $^{(17)}$. Thus, receiving nutritional counseling during prenatal care is an important factor to protect women from preeclampsia(12).

Regarding the identification of risk factors predisposing to preeclampsia, satisfactory results have been reported on the benefits of aspirin administered at a low dose $(150 \mathrm{mg})$ in pregnant women at high risk for developing preeclampsia. Its use can reduce the prevalence of this disease when started as soon as the 16 th gestational week ${ }^{(18)}$.

Due to the high costs of health services treating preeclampsia and its sequelae, prevention through the prescription of low doses of aspirin is an economically feasible alternative, because it is a safe medication to be used during pregnancy, of relatively low cost, and widely available in the health services network; however, further evidence is still needed to support the adoption of strategies like this ${ }^{(19)}$.

Thus, still regarding aspects such as the cost related to the intervention to predict preeclampsia 
in economically fragile public health systems, an algorithm capable of predicting the occurrence of preeclampsia was created based on a cohort study. This predictions was made on the basis of "less complex" data such as maternal characteristics (e.g. age, self-reported skin color, parity, previous history of preeclampsia, smoking, family history of preeclampsia, hypertension, diabetes mellitus, and body mass index) in association with mean arterial pressure within the defined range in the first trimester of pregnancy ${ }^{(20)}$. In practical terms, this would represent the possibility of predicting preeclampsia at low cost and with high efficacy according through this algorithm. In turn, early detection will allow the pregnant woman in higher risk groups to adopt aspirin therapy as well as the follow-up of pregnant women at higher risk by tertiary services.

In this scenario, nurses play a key role in the care and education of women at risk. Since preeclampsia has high morbidity and mortality rates and unfavorable outcomes, it is essential that quality nursing, based on the best scientific evidence, provides assistance to women and their families, aiming at the early detection of risk factors and the better clinical management of the disease. It is also emphasized that because nurses are the professionals more present in the care offered to mothers and newborns, they are able to provide the necessary continuous surveillance for this complicated and challenging public health problem.

In summary, the mentioned data allow us to describe the profile of pregnant women seeking care in the Family Health Strategy, making it possible to compare such profile with those reported in other national and international studies.

\section{Conclusion}

In view of the above, it was concluded that some of the risk factors for development of preeclampsia were present in the records evaluated, and statistical significance was observed for primiparity, chronic hypertension, diabetes mellitus and obesity.

\section{Aknowledgements}

To the Conselho Nacional de desenvolvimento Científico e Tecnológico for the Productivity Grant provided to Mônica Oliveira Batista Oriá, according to Process no 306555/2016-6.

\section{Collaborations}

Ferreira ETM, Moura NS, Gomes MLS and Oriá MOB contributed to the design of the project. Silva EG and Guerrero MGS contributed to the analysis and interpretation of the data. All the authors contributed to the writing of the article, relevant critical revision of the intellectual content, and to the final approval of the version to be published.

\section{References}

1. Adeyinka O, Jukic AM, McGarvey ST, MuasauHoward BT, Faiai M, Hawley. Predictors of prenatal care satisfaction among pregnant women in American Samoa. BMC Pregnancy Childbirth. 2017; 17(1):381. doi: https://doi.org/10.1186/ s12884-017-1563-6

2. Al-rubaie ZTA, Askie LM, Ray JG, Hudson HM, Lord SJ. The performance of risk prediction models for pre-eclampsia using routinely collected maternal characteristics and comparison with models that include specialised tests and with clinical guideline decision rules: a systematic review. Int J Obstetr Gynaecol. 2016; 123:1441-52. doi: https://doi.org/10.1111/1471-0528.14029

3. Erez O, Romero R, Maymon E, Chaemsaithong P, Done B, Pacora P, et al. The prediction of late-onset preeclampsia: results from a longitudinal proteomics study. PLoS One. 2017; 12(7):e0181468. doi: https://doi.org/10.1371/journal.pone.0181468

4. Ramos JGL, Sass N, Costa SHM. Preeclampsia. Rev Bras Ginecol Obstet. 2017; 39(9):496-12. doi: https://doi.org/10.1055/s-0037-1604471

5. Wright D, Syngelaki A, Akolekar R, Poon LC, Nicolaides KH. Competing risks model in screening for preeclampsia by maternal characteristics and medical history. Am J Obstet Gynecol. 2015; 213(1):62.e1-10. doi: https://doi.org/10.1016/j. ajog.2015.02.018 
6. Cadavid AP. Aspirin: the mechanism of action revisited in the context of pregnancy complications. Front Immunol. 2017; 8:261. doi: https://doi. org/10.3389/fimmu.2017.00261

7. The American College of Obstetricians and Gynecologists. Committee Opinion No. 638: first-trimester risk assessment for early-onset preeclampsia. Obstet Gynecol. 2015; 126(3):e25-7. doi: doi.org/10.1097/AOG.0000000000001049

8. Malachias MVB, Gomes MAM, Nobre F, Alessi A, Feitosa AD, Coelho EB. 7th Brazilian Guideline of Arterial Hypertension: chapter 2 diagnosis and classification. Arq Bras Cardiol. 2016; 107(3Supl.3):1-83. doi: http://dx.doi. org/10.5935/abc.20160152

9. O'Gorman N, Wright D, Syngelaki A, Akolekar R, Wright A, Poon LC, et al. Competing risks model in screening for preeclampsia by maternal factors and biomarkers at 11-13 weeks gestation. Am J Obstet Gynecol. 2016; 214(1):103.e1-e12. doi: dx.doi.org/10.1016/j.ajog.2015.08.034

10. Linhares JJ, Macêdo NMQ, Arruda GM, Vasconcelos JLM, Saraiva TV, Ribeiro AF. Fatores associados à via de parto em mulheres com pré-eclâmpsia. Rev Bras Ginecol Obstet. 2014; 36(6):259-63. doi: dx.doi.org/10.1590/S0100-720320140004812

11. Silva PLN, Oliveira JS, Santos APO, Vaz MDT. Cuidados pré-natais e puerperais às gestantes de um centro de saúde de Minas Gerais quanto ao risco de pré-eclâmpsia: aspectos clínicos, nutricionais e terapêuticos. J Health Biol Sci. 2017; 5(4):346-51. doi: http://dx.doi.org/10.12662/2317-3076jhbs. v5i4.1222.p346-351.2017

12. Grum T, Seifu A, Abay M, Angesom T, Tsegay L. Determinants of pre-eclampsia/eclampsia among women attending delivery services in selected public hospitals of Addis Ababa, Ethiopia: a case control study. BMC Pregnancy Childbirth. 2017; 7(1):307. doi: dx.doi.org/10.1186/s12884-0171507-1
13. Guerrier G, Oluyide, B, Keramarou M, Grais, RF. Factors associated with severe preeclampsia and eclampsia in Jahun, Nigeria. Int J Womens Health. 2013; 5:509-13. doi: dx.doi.org/10.2147/IJWH. S47056

14. Monteiro ALS, Soares MC, Maciel PC, Nascimento DJ. Avaliação epidemiológica de gestantes hipertensas crônicas da maternidade HC-UFPR. Rev Med UFPR. 2017; 4(1):17-22. doi: dx.doi. org/10.5380/rmu.v1i1

15. Lima JP, Veras LLN, Pedrosa EKFS, Oliveira GSC, Guedes MVC. Socioeconomic and clinical profile of pregnant women with Gestational Hypertension Syndrome. Rev Rene. 2018; 19:e3455. doi: dx.doi. org/10.15253/2175-6783.2018193455

16. Stubert J, Reister F, Hartmann S, Janni W. The risks associated with obesity in pregnancy. Dtsch Arztebl Int. 2018; 115(16):276-83. doi: dx.doi. org/10.3238/arztebl.2018.0276

17. Schummers L, Hutcheon JA, Bodnar LM, Lieberman E, Himes KP. Risk of adverse pregnancy outcomes by prepregnancy body mass index: a populationbased study to inform prepregnancy weight loss counseling. Obstet Gynecol. 2015; 125(1):133-43. doi: 10.1097/AOG.0000000000000591

18. Roberge S, Odibo AO, Bujold E. Aspirin for the prevention of preeclampsia and intrauterine grow restriction. Clin Lab Med. 2016; 36(2):319-29. doi: dx.doi.org/10.1016/j.cll.2016.01.013

19. Mone F, Mulcahy C, McParland P, McAuliffe FM. Should we recommend universal aspirin for all pregnant women?. Am J Obstet Gynecol. 2017; 216(2):141.e1-e5. doi: dx.doi.org/10.1016/j. ajog.2016.09.086

20. Rocha RS, Alves JAG, Moura SBMH, Araujo Júnior E, Peixoto AB, Santana EFM, et al. Simple approach based on maternal characteristics and mean arterial pressure for the prediction of preeclampsia in the first trimester of pregnancy. J Perinat Med. 2017; 45(7):843-9. doi: dx.doi.org/10.1515/jpm2016-0418 